\title{
Development and psychometric testing of a Gastric Cancer Behavioural Risk Assessment Inventory (GC-BRAI)
}

Sadigheh Razavi, ${ }^{1}$ Hassan Mahmoodi, ${ }^{2}$ Hassan Rezaei Pandari, ${ }^{1}$ Parvin Sarbakhsh ${ }^{3}$ and Abdolreza Shaghaghi ${ }^{1}$

${ }^{1}$ Department of Health Education and Promotion, Faculty of Health, Tabriz University of Medical Sciences, Tabriz, Islamic Republic of Iran (Correspondence to: A. Shaghaghi: ar.shaghaghi@gmail.com; shaghaghir@tbzmed.ac.ir). ${ }^{2}$ Social Determinants of Health (SDH) Research Center, Research Institute for Health Development, Kurdistan University of Medical Sciences, Sanandaj, Islamic Republic of Iran. ${ }^{3 B i o-s t a t i s t i c s ~ a n d ~ E p i d e m i o l o g y ~}$ Department, Faculty of Health, Tabriz University of Medical Sciences, Tabriz, Islamic Republic of Iran.

\begin{abstract}
Background: Gastric cancer (GC) is one of the most common cancers worldwide. There is no disease-specific tool for GC risk assessment in research and practice settings within the Iranian sociocultural context.

Aims: To develop and assess the psychometric properties of the Gastric Cancer Behavioral Risk Assessment Inventory (GC-BRAI) in GC patients in Northwest Islamic Republic of Iran.

Methods: Face-to-face interviews were performed on a convenient sample of $175 \mathrm{GC}$ patients and a purposive sample of 350 matched non-GC patients as a control group. Exploratory factor analysis (EFA) and confirmatory factor analysis (CFA) were performed to appraise the structure validity of GC-BRAI and examine its possible latent constructs.

Results: The designed instrument with its 5 latent factors indicated acceptable internal consistency (0.72), reliability (0.99) and fit indices $\left(X^{2} /\right.$ degrees of freedom $=2.24$, root mean square error of approximation $=0.049$, adjusted goodness of fit index $=0.91$ and root mean square residual $=0.085$ ). The identified components were specific nutritional behaviours, typical daily diet, routine heartburn-causing behaviours or foods in diet, daily use of rice and smoked foods, and tobacco smoking/alcohol consumption, which all indicated a significant association $(P=0.0001)$ with high-risk of GC.
\end{abstract}

Conclusions: GC-BRAI can be considered a feasible tool to measure individual GC risk and a reliable data collection instrument in tailor-made risk reduction interventional programmes.

Keywords: gastric cancer, health behaviour, psychometrics, questionnaire design

Citation: Razavi S; Mahmoodi H; Pandari H; Sarbakhsh P; Shaghaghi A. Development and psychometric testing of a Gastric Cancer Behavioural Risk Assessment Inventory (GC-BRAI). East Mediterr Health J. 2021;27(1):50-58. https://doi.org/10.26719/emhj.20.103

Received: 30/03/19; accepted: 13/01/20

Copyright (C) World Health Organization (WHO) 2021. Open Access. Some rights reserved. This work is available under the CC BY-NC-SA 3.0 IGO license (https://creativecommons.org/licenses/by-nc-sa/3.o/igo).

\section{Introduction}

Cancer is among the leading causes of death worldwide after cardiovascular disease and the second most prominent cause of death in less-developed countries $(1,2)$. Gastric cancer (GC) ranks among the top causes of cancer-related deaths worldwide, with $\sim 1$ million new cases detected annually and an estimated $783000(8.2 \%)$ deaths $(3,4)$. Almost $75 \%$ of new cases of GC occur in developing countries $(5,6)$. In the Islamic Republic of Iran, GC is the leading cause of cancer mortality in men and the second main cause in women. The reported standardized incidence rate of GC for Iranian men and women is 19.6 and 10.0 per 100000 population, respectively (7). Although GC-induced mortality has declined significantly in most developed countries over the past few decades, it is still high in some Asian, Eastern European and South American countries $(8,9)$. During the past few years, the incidence and mortality of GC have increased in the Islamic Republic of Iran (10), and GC has become the second most common malignancy after lung cancer and the leading cause of cancer deaths (11). GC is the most prevalent cancer among Iranian men and the third most common among women (12). The highest incidence of cancer has been reported in the north and northwest of the country, mainly in the Gilan, Mazandaran, Golestan, Ardabil and East Azarbaijan Provinces (13).

Previous studies have shown that modifications in diet and food preparation methods can reduce GC incidence (14). Based on empirical research evidence, behavioural risk factors currently are important determinants of GC (15). GC prevention strategies, therefore, are focused on behavioural changes (16).

GC is a multifaceted disease and a wide range of environmental and genetic factors could play a role in its distribution (17). The major reported risk factors for GC include: family history; Helicobacter pylori infection (18); dietary habits such as consumption of salt-cured and smoked meat, fried foods, and spicy and nitratecontaining foods; consumption of alcoholic drinks; cigarette smoking; and occupational exposure to heavy metals such as cadmium and lead (15). Suggested GC protective measures include daily consumption of adequate servings of green vegetables and fresh fruit, especially citrus fruits with high vitamin C content (19).

Several studies have used exploratory factor analysis (EFA) to identify potential dietary risk factors for GC $(20,21)$. However, no study has investigated the possible relationship between dietary/nondietary behavioural 
patterns and development of GC in Iranian or other Persian-speaking populations. Through classifying individual risk factors into exposure categories and aggregation of these potential risk factors into distinct risk components, the GC risk pathways and behavioural patterns can better be explained. The purported advantages of lifestyle change in prevention of GC mean that targeting modifiable risk factors (e.g., poor dietary habits) is considered essential in interim interventional programmes (21). The main encouragements for the present study were: current trends in the incidence of GC in the Islamic Republic of Iran (13); empirical evidence about the effectiveness of behaviour change on the epidemiological profile of GC (21); and lack of a specific tool to appraise individuals' GC risk pattern. We aimed to develop and psychometrically assess a definitive questionnaire for GC risk assessment that might be applicable for risk stratification and mitigation in research and practice settings.

\section{Methods}

\section{Participants}

This case-control study consisted of a convenience sample of $175 \mathrm{GC}$ patients and a purposive sample of 350 ageand sex-matched non-GC controls who were admitted to 3 hospitals (Imam Reza, Shahid Ghazi Tabatabai, and Alinasab) with oncology wards in Tabriz, East Azarbaijan Province, Islamic Republic of Iran.

The study was conducted in accordance with the ethical standards in the Declaration of Helsinki, and the Medical Ethics Review Board of Trustees (MERBoT) in Tabriz University of Medical Science approved all of the study procedures (approval number: 5/D/1026302-139712-05). Inclusion criteria for cases were diagnosis of GC and age 18-85 years. Inclusion criteria for controls were admission for any disease other than GC and age 18-85 years. The exclusion criterion for GC patients was any type of concurrent cancer due to immunodeficiency. The exclusion criterion for the control group was GC caused by metastasis from an extra-gastrointestinal tract malignancy. The study participants were also excluded if they had any other critical health condition.

The rounded up (to the nearest 5) proportions of the respondents (25\% in the controls and $45 \%$ in the cases) that reported a high-risk dietary habit (e.g., reusing cooking oil) in the study of Salvador et al. (22) were utilized to decide on the study sample size. To improve precision of estimates, a one-to-many matching approach (2:1 ratio of controls to cases), type 1 error of 0.05 and test power of 0.90 were deemed as prior statistical parameters in STATA version 13 software (StataCorp LP, College Station, TX, USA). Thus, a minimum sample size of 175 subjects per group was estimated to be appropriate to satisfy the statistical significance threshold, although 175 patients were included in the case group and 350 matched individuals in the control group. Face-to-face interviews were conducted for data collection purposes from 9 April 2017 to 20 June 2018. The study participants gave their written informed consent to participate in the study.

\section{Instrument development stages}

The item pool was based on an extensive literature search and interviews with relevant healthcare professionals. Thus, 22 items were generated and validity and reliability appraisal procedures were used to assess psychometric properties of the adapted instrument. The preliminary draft of the Gastric Cancer Behavioral Risk Assessment Inventory (GC-BRAI) was sent to 12 healthcare professionals for their comments on face and content validities of the questionnaire, including lucidity of the wording and ability of the items to communicate the messages of interest to potential readers. They were also asked to comment on a 5-point Likert scale about importance, necessity or redundancy of the items. The content validity index and content validity ratio were used to quantitatively validate the designed instrument. The calculated content validity index (0.68) and content validity ratio (0.83) were in the vicinity of the acceptable range (23); therefore, no changes were made to the preliminary draft of the GCBRAI. A sample of GC and non-GC patients ( 15 from each group) was approached in the next step to canvass their opinions about the simplicity, clarity and consistency of the items. Minor modifications were made to the items based on these comments.

\section{Reliability of the GC-BRAI}

We estimated the test-retest reliability of the scales and Cronbach's $\alpha$ as the measure of internal consistency and intraclass correlation coefficient (ICC) as the reliability index of the constructed tool (60 GC and non-GC patients completed the scale within 30 days). Exploratory factor analysis (EFA) was performed by main factors analysis using Varimax rotation on a randomly selected sample of half of the GC patients $(n=78)$ and non-GC patients ( $n=$ 77) to assess construct validity of the scale. To include an item in EFA, the minimum factor load was assumed to be 0.3. AMOS software was used to evaluate the factor construct and to determine the goodness of fit indices (GFIs).

The scale items' response choices were considered as: not at all (1), rarely (2), sometimes (3), most of the time (4) and always (5). Some of the items were positive statements representing proven preventive impact on GC, that is, Q1, Q2, Q3, Q5, Q12 and Q16; therefore, they were reverse scored so that the higher score implied a high-risk behavioural pattern of GC. Respecting the number of composed scale's items (22), values of the respondents' total score was considered to be in the range of 22-110, with higher score reflecting a higher risk of GC.

Data analysis results for continuous variables was presented as mean (standard deviation) and for categorical variables as numbers and frequencies. Conditional logistic regression analysis was used for data analysis because of the one-to-many matched case-control design, and having a series of observations that were not independent but matched for sex and age. Conditional logistic regression is an extension of logistic regression that allows one to take into account stratification and matching in the data analysis. The data analysis was performed using R version 3.6.1 (survival package). 


\section{Results}

There were 175 patients with GC in the case group: 118 (67.4\%) male and 57 (32.6\%) female, with a mean age of 57.03 (12.23) years and mean body mass index (BMI) of 25.72 (4.25) kg/m2. There were 350 controls: 236 (67.4\%) male and 114 (32.6\%) female, with a mean age of 57.03 (12.21) years and mean BMI of 24.9 (2.96) kg/m2. BMI differed significantly between the groups $(P=0.012)$. The approximated Cronbach's $\alpha 0.72$ and ICC 0.99 represented acceptable internal consistency (24) and reliability of the developed scale (25) over time.

The Kaiser-Meyer-Olkin measure of sampling adequacy (0.771) and Bartlett's test of sphericity (1883.35, $\mathrm{df}=231, \mathrm{P}<0.001)$ as preanalysis verification indices to perform factor analysis on the study data were in the vicinity of acceptable ranges (26).

The EFA analysis results demonstrated a 5-factor solution representing that the designed scale's items can be classified effectively into the 5 distinct constructs according to their loadings for the components that together accounted for $47.46 \%$ of the total variance (Table 1).
The identified latent components were specific nutritional behaviours, typical daily diet, routine heartburn causing behaviours or foods in diet, daily use of rice and smoked foods, and tobacco smoking and alcohol consumption (Table 2).

To verify the number of factor solutions and give a visual representation of the possible factor solutions, we analysed the scree plot (Figure 1). The plot indicated a levelling off the Eigenvalues after 5 factors were extracted. The first extracted latent variable explained a disproportionate amount of the variability in the data set. However, due to the inherent subjectivity that is involved in interpreting scree plots and considering theoretical cohesion of the other variables, the appropriate number of variables was based on the study data structure.

The prior factor structure of the GC-BRAI, which had been extracted by EFA, was also examined by confirmatory factor analysis (CFA) to verify a good data fit with the hypothesized factorial structure. CFA was conducted on a sample comprising the other half of the GC patients $(n=77)$ added to the randomly selected sample of non-GC patients $(n=78)$. The $\chi 2 / \mathrm{df}$ ratio $=2.24$ $(P<0.05)$, root mean square residual $=0.085$, GFI $=0.86$,

\begin{tabular}{|c|c|c|c|c|c|c|}
\hline \multirow[t]{2}{*}{ Items } & & \multicolumn{5}{|c|}{ Latent variables } \\
\hline & & 1 & 2 & 3 & 4 & 5 \\
\hline 1 & Did you generally eat vegetables with meals? & 0.778 & & & & \\
\hline 2 & Did you eat at least two servings of fruit daily? & 0.663 & & & & \\
\hline 3 & Did you eat nuts every day or once every few days? & 0.627 & & & & \\
\hline 4 & Did you eat nuts and fruit at night before going to bed? & 0.622 & & & & \\
\hline 5 & Did you eat soybeans? & 0.542 & & & & \\
\hline 6 & Did you eat fruits like apples and cucumbers with peel? & -0.465 & & & & \\
\hline 7 & $\begin{array}{l}\text { Did you use ready-to-eat meat products like sausage every day } \\
\text { or once every few days? }\end{array}$ & & 0.742 & & & \\
\hline 8 & Did you routinely eat canned foods like tuna fish every day? & & 0.673 & & & \\
\hline 9 & Did you drink bottled water every day? & & 0.637 & & & \\
\hline 10 & Did you generally drink carbonated beverages with meals? & & 0.636 & & & \\
\hline 11 & Did you generally eat your meal with spicy condiments? & & & 0.611 & & \\
\hline 12 & Did you have normal bowel movement every day? & & & 0.594 & & \\
\hline 13 & $\begin{array}{l}\text { Did you go to bed immediately after eating on day and/or at } \\
\text { night? }\end{array}$ & & & 0.531 & & \\
\hline 14 & Did you generally eat pickles with meals? & & & 0.523 & & \\
\hline 15 & Did you immediately drink tea after meals? & & & 0.424 & & \\
\hline 16 & Did you routinely use Iranian rice crops in your daily diet? & & & & 0.829 & \\
\hline 17 & Did you routinely use imported rice crops in a daily diet? & & & & 0.816 & \\
\hline 18 & Did you eat smoked rice routinely? & & & & -0.306 & \\
\hline 19 & Did you drink domestic or homemade alcoholic beverages? & & & & & 0.724 \\
\hline 20 & Did you smoke every day? & & & & & 0.716 \\
\hline 21 & Did you wake up at night because of heartburn? & & & & & 0.491 \\
\hline 22 & $\begin{array}{l}\text { Did you smoke hookah at least once every week or every two } \\
\text { weeks? }\end{array}$ & & & & & 0.491 \\
\hline
\end{tabular}




$\begin{aligned} & \text { Table } 2 \text { The latent variables' eigenvalues and percentage of explained variance for the Gastric Cancer Behavioral Risk Assessment } \\
& \text { Inventory (GC-BRAI) }\end{aligned}$
\begin{tabular}{llcc} 
Latent variables & Initial Eigenvalues & $\%$ of explained variance & $\begin{array}{c}\text { \% of cumulative } \\
\text { variance }\end{array}$ \\
Specific nutritional behaviors & 3.72 & 16.91 & 16.91 \\
Canned and processed foods in daily diet & 2.63 & 11.98 & 28.89 \\
Routine heartburn causing behaviors or foods in diet & 1.55 & 7.06 & 35.95 \\
Daily use of rice and smoked foods & 1.31 & 5.97 & 41.93 \\
Tobacco smoking and alcohol drinking & 1.21 & 5.52 & 47.46 \\
\hline
\end{tabular}

root mean square error of approximation $=0.049$ ) and adjusted GFI = 0.91 demonstrated an acceptable model fit with the 5-factor solution (Figure 2). The item-to-factors correlations and the observed correlations among the 5 factors (Figure 2) were significant $(P<0.05)$.

Mean scores of the GC and non-GC patients based on each single item, identified factors and total GC-BRAI scores are shown in Table 3. Except for eating fruits like apples and cucumbers with peel, the identified latent variables and total GC-BRAI scores were significantly lower in non-GC than in GC patients (Table 3). Based on the data in Figure 2 and Table 3, the following could be considered as high-risk behavioural patterns for GC: high-risk nutritional/non-nutritional habits such as eating late at night and before going to bed; not having the recommended portions of fruits and vegetables in the daily diet; frequent inclusion of processed and canned foods in the daily diet; routinely having foods or behaviours that cause heartburn; routine consumption of rice and smoked foods; and regular tobacco smoking and alcohol consumption.

\section{Discussion}

Given the lack of a common and intelligible tool for application in research and practice settings to recognize people at greater risk for $\mathrm{GC}$, this study was conducted to design and appraise psychometric properties of GC-BRAI in a sample of GC and non-GC patients in the Islamic Republic of Iran. The data indicated an acceptable validity and reliability of the constructed 22-item tool with 5 dimensions. The initial conceptual factors and items were retrieved through an extensive literature search and a preliminary draft of the developed scale was verified by a panel of experts. The designed instrument confirmed an acceptable internal consistency, reliability and a good fitting measurement model. The GC-BRAI identified 5 latent variables that represented potential GC-causing high-risk lifestyle behaviour.

Figure 1 Scree plot representing the eigenvalues of the extracted variables obtained in a principal-component analysis of the Gastric Cancer Behavioral Risk Assessment Inventory (GC-BRAI).

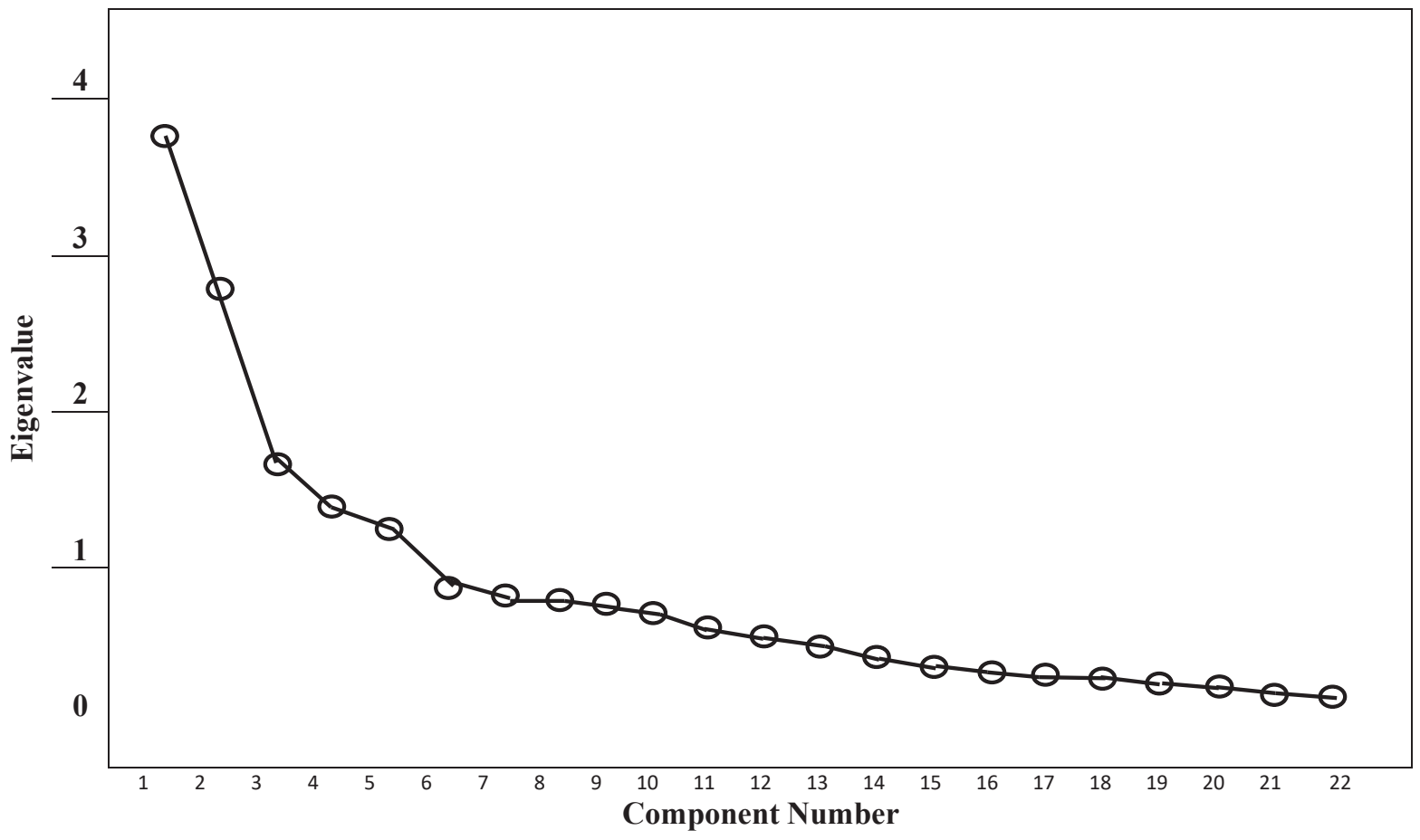



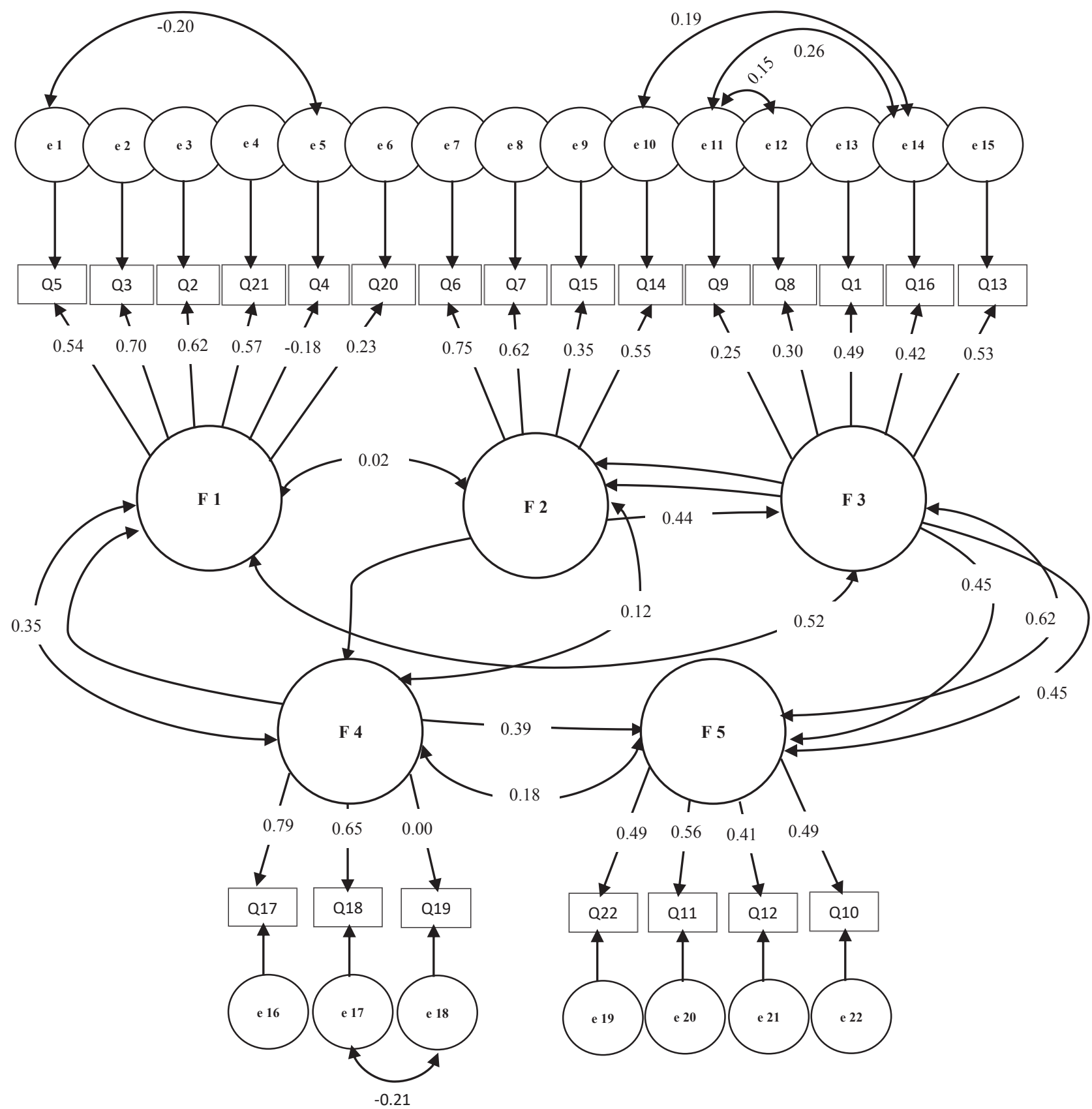

F1: Specific nutritional behaviors

F2: Canned and processed foods in daily diet

F3: Routine heartburn causing behaviors or foods in diet

F4: Daily use of rice and smoked foods

F5: Tobacco smoking and alcohol drinking 
Our results agree with those reported in the literature. Frequent consumption of salty food, heavy smoking and high alcohol consumption are suggested to increase the risk of GC (27-31). History of gastroesophageal reflux, low fruit and vegetable consumption, intake of nitrites in canned and processed foods, low amounts of nuts and peanut butter consumption are also reported to increase the risk of GC (32-34). All these results provided empirical support for the psychometric soundness and utility of the GC-BRAI.

GC-BRAI is a simple tool for assessing the risk profile for development of GC and could be helpful to healthcare professionals and researchers seeking to identify GC risk of their target groups. The instrument could also be used in assessment of lifestyle as a part of regular health assessment programmes and in health research to assess effectiveness of the GC-targeted interventions, or to identify important behavioural antecedents of the disease in GC patients. In more tailored applications, GCBRAI may be used to reveal insights into the level and components of GC risk of individuals.

We made efforts to have a diverse team of researchers in order to collect a range of opinions about the validity of the items in GC-BRAI and its cross-country applicability (35). The study sample consisted only of Iranian GC and non-GC patients, which may restrict the applicability of GC-BRAI in other cultures. Crosscultural differences in daily diet and lifestyle could cause heterogeneous variance in responses. Therefore, universal applicability of the developed tool should be considered with caution given the unrepresentativeness of our study sample. Future research may alleviate these limitations by conducting crosscultural tests of the GC-BRAI on broader and more diverse populations. Reliance on self-reported

\begin{tabular}{|c|c|c|c|c|}
\hline \multicolumn{2}{|c|}{ GC-BRAI Items } & \multicolumn{2}{|c|}{ Mean (SD) } & \multirow[t]{2}{*}{$\mathbf{P}$} \\
\hline & & \multirow{2}{*}{$\begin{array}{c}\begin{array}{c}\text { GC patients } \\
(\mathbf{n}=\mathbf{1 7 5})\end{array} \\
3.60(1.12)\end{array}$} & $\begin{array}{l}\text { Non GC } \\
\text { patients } \\
(n=350)\end{array}$ & \\
\hline 1 & Did you generally eat vegetables with meals? & & $2.75(1.17)$ & 0.0001 \\
\hline 2 & Did you eat at least two servings of fruits daily? & $3.82(1.24)$ & $2.75(1.25)$ & 0.0001 \\
\hline 3 & Did you eat nuts every day or once every few days? & $4.14(0.90)$ & $3.46(1.02)$ & 0.0001 \\
\hline 4 & Did you eat nuts and fruits at nights before going to bed? & $2.09(1.15)$ & $3.04(1.18)$ & 0.0001 \\
\hline 5 & Did you eat soybeans? & $3.75(0.89)$ & $3.31(1.16)$ & 0.0001 \\
\hline 6 & Did you eat fruits like apples and cucumbers with peel? & $3.07(1.40)$ & $3.18(1.32)$ & 0.3840 \\
\hline Subscale & Specific nutritional behaviours & $18.41(3.07)$ & $15.48(2.87)$ & 0.0001 \\
\hline 7 & $\begin{array}{l}\text { Did you use ready-to-eat meat products like sausage every day or once } \\
\text { every few days? }\end{array}$ & $2.14(0.95)$ & $1.73(0.89)$ & 0.0001 \\
\hline 8 & Did you routinely eat canned foods like tuna fish every day? & $2.53(0.98)$ & $1.95(0.94)$ & 0.0001 \\
\hline 9 & Did you drink bottled water every day? & $2.20(1.11)$ & $1.89(1.02)$ & 0.007 \\
\hline 10 & Did you generally drink carbonated beverages with meals? & $2.78(1.21)$ & $2.33(1.18)$ & 0.0001 \\
\hline Subscale & Canned and processed foods in daily diet & $9.66(2.82)$ & $7.90(2.75)$ & 0.0001 \\
\hline 11 & Did you generally eat your meal with spicy condiments? & $3.12(1.18)$ & $2.28(1.16)$ & 0.0001 \\
\hline 12 & Did you have normal bowel movement every day? & $3.05(1.06)$ & $3.74(1.28)$ & 0.0001 \\
\hline 13 & Did you go to bed immediately after eating on day and/or at night? & $3.41(1.21)$ & $2.46(1.23)$ & 0.0001 \\
\hline 14 & Did you generally eat pickles with meals? & $3.61(1.09)$ & $2.88(1.22)$ & 0.0001 \\
\hline 15 & Did you immediately drink tea after meals? & $4.00(1.41)$ & $3.00(1.36)$ & 0.0001 \\
\hline Subscale & Routine heartburn causing behaviours or foods in diet & $17.21(2.96)$ & $14.39(2.98)$ & 0.0001 \\
\hline 16 & Did you routinely use Iranian rice crops in your daily diet? & $3.26(1.39)$ & $2.87(1.31)$ & 0.0050 \\
\hline 17 & Did you routinely use imported rice crops in a daily diet? & $3.40(1.33)$ & $2.63(1.33)$ & 0.0001 \\
\hline 18 & Did you eat smoked rice routinely? & $2.44(1.30)$ & $2.16(1.20)$ & 0.0170 \\
\hline Subscale & Daily use of rice and smoked foods & $9.10(2.47)$ & $7.68(2.46)$ & 0.0001 \\
\hline 19 & Did you drink domestic or homemade alcoholic beverages? & $1.29(0.79)$ & $1.08(0.45)$ & 0.0001 \\
\hline 20 & Did you smoke every day? & $2.20(1.66)$ & $1.50(1.20)$ & 0.0001 \\
\hline 21 & Did you wake up at night because of heartburn? & $2.61(1.32)$ & $1.68(1.02)$ & 0.0001 \\
\hline 22 & Did you smoke hookah at least once every week or every two weeks? & $1.80(1.39)$ & $1.27(0.78)$ & 0.0001 \\
\hline Subscale & Tobacco smoking and alcohol drinking & $7.90(3.23)$ & $5.55(2.27)$ & 0.0001 \\
\hline \multicolumn{2}{|c|}{ Total GC-BRAI score } & $64.32(8.29)$ & $54.14(7.05)$ & 0.0001 \\
\hline
\end{tabular}


lifestyle behaviour could have been another source of bias in our study. Further research is recommended by adding other sources of measurement when dealing with individual GC antecedents.

Although we collected data through positively and negatively expressed questions, personal reservations to answer a specific questions, for example, about alcohol consumption or smoking, should be considered in the interpretation of the findings. The GC-BRAI items were focused on individual risk factors and probable effects of environmental factors, such as pollutants, food toxicities and psychosocial covariates, were not studied. Inclusion of these variables and examination of the possible pathways between GC and environmental and community level factors is recommended in future studies.

\section{Conclusion}

There has been a paucity of research on the behavioural risk factors for GC, which has been partially hampered by the absence of a valid tool to measure individual GC risk. Therefore, GC-BRAI could provide research evidence to be used for prevention of GC. GC-BRAI can be used to measure individual-level GC risk, which justifies its applicability in tailor-made risk reduction interventional programmes. This concise scale could help with research on GC risk assessment and ultimately contribute to prevention or early detection of the disease.

Funding: This study was partially supported by a grant from the Tabriz University of Medical Sciences (grant number: 5/D/1045305-1396-01-15).

Competing interests: None declared.

\section{Mise au point et test psychométrique d'un inventaire d'évaluation du risque comportemental de cancer de l'estomac (Gastric Cancer Behavioural Risk Assessment Inventory, GC-BRAI)}

\section{Résumé}

Contexte : Le cancer de l'estomac est l'un des cancers les plus fréquents dans le monde. Dans le contexte socioculturel iranien, il n'existe pas d'outil spécifique à la maladie pour l'évaluation du risque de cancer de l'estomac dans le cadre de la recherche et de la pratique.

Objectifs: Mettre au point et évaluer les propriétés psychométriques de l'inventaire d'évaluation du risque comportemental de cancer de l'estomac chez les patients atteints de ce type de cancer dans le nord-ouest de la République islamique d'Iran.

Méthodes : Des entretiens en présentiel ont été réalisés sur un échantillon de commodité de 175 patients atteints de cancer de l'estomac et sur un échantillon ciblé de 350 patients appariés non atteints de cancer de l'estomac comme groupe témoin. Une analyse factorielle exploratoire et une analyse factorielle confirmatoire ont été effectuées pour évaluer la validité structurale du GC-BRAI et examiner ses possibles structures latentes.

Résultats: Les résultats de l'analyse factorielle exploratoire et de l'analyse factorielle confirmatoire ont montré que le modèle à cinq facteurs avait des indices d'ajustement acceptables ( $\chi 2$ /degrés de liberté $=2,24$, erreur quadratique moyenne d'approximation $=0,049$, indice d'ajustement comparatif $=0,86$, validité ajustée de l'indice d'ajustement $=0,91$, validité de l'indice d'ajustement $=0,93$ et résidu quadratique moyen $=0,085)$. Les éléments identifiés étaient les comportements nutritionnels spécifiques, le régime alimentaire quotidien typique, les comportements ou aliments courants provoquant des brûlures d'estomac, la consommation quotidienne de riz et d'aliments fumés et la consommation de tabac/alcool, qui indiquaient tous une association significative $(p=0,0001)$ avec un risque élevé de cancer de l'estomac.

Conclusions : Le GC-BRAI peut être considéré comme un outil permettant de mesurer le risque individuel lié au cancer de l'estomac et un instrument fiable de collecte de données dans des programmes interventionnels de réduction du risque personnalisés.

$$
\begin{aligned}
& \text { إعداد قائمة لتقييم المخاطر السلوكية المرتبطة بسرطان المعدة، وإخضاعها لاختبارات القياس النفسي }
\end{aligned}
$$

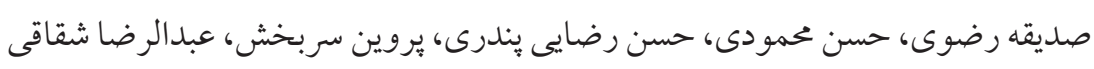

$$
\begin{aligned}
& \text { الخلاصة }
\end{aligned}
$$

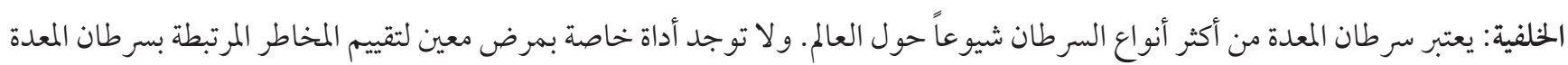

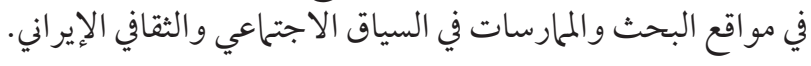

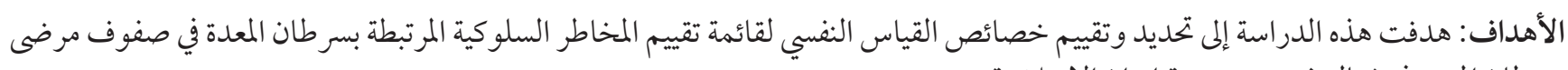

$$
\begin{aligned}
& \text { سرطان المعدة في شمال غرب جمهورية إيران الإسلامية. }
\end{aligned}
$$




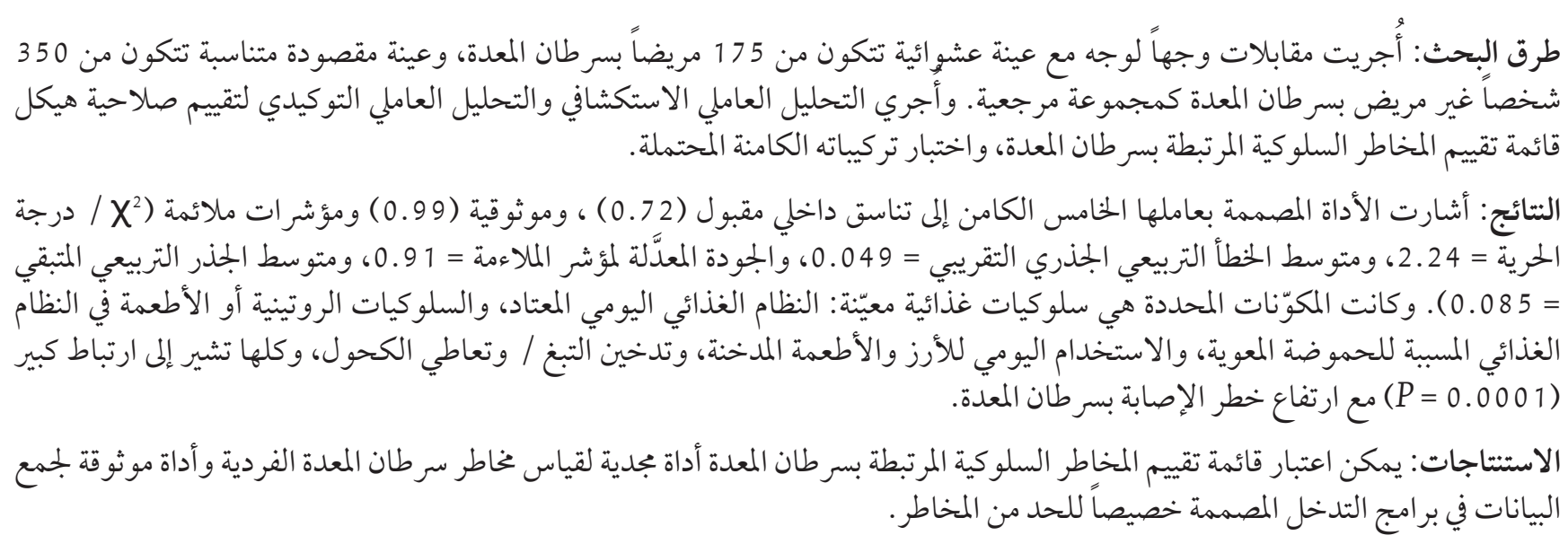

\section{References}

1. Jemal A, Bray F, Center MM, Ferlay J, Ward E, Forman D. Global cancer statistics. CA Cancer J Clin. 2011 Mar-Apr;61(2):69-90. http://dx.doi.org/10.3322/caac.20107 PMID:21296855

2. Aghajani H, Eatemad K, Goya M, Ramezani R, Modirian MNF, Nadali F. Iranian annual national cancer registration report 2008-2009. Tehran: Center for Disease Control \& Prevention, Noncommunicable Diseases Unit, Cancer Office; 2011 (in Persian)

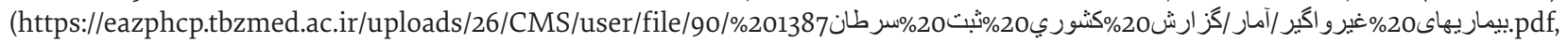
accessed 2 July 2020).

3. Bray F, Ferlay J, Soerjomataram I, Siegel RL, Torre LA, Jemal A. Global cancer statistics 2018: GLOBOCAN estimates of incidence and mortality worldwide for 36 cancers in 185 countries. CA Cancer J Clin. 2018 Nov;68(6):394-424. http://dx.doi.org/10.3322/ caac.21492 PMID:30207593

4. Rawla P, Barsouk A. Epidemiology of gastric cancer: global trends, risk factors and prevention. Prz Gastroenterol. 2019; 14(1):2638. http://dx.doi.org/10.5114/pg.2018.80001 PMID:30944675

5. Fock KM, Ang TL. Epidemiology of Helicobacter pylori infection and gastric cancer in Asia. J Gastroenterol Hepatol. 2010 Mar;25(3):479-86. http://dx.doi.org/10.1111/j.1440-1746.2009.06188.x PMID:20370726

6. Yang L. Incidence and mortality of gastric cancer in China. World J Gastroenterol WJG. 2006 Jan;12(1):17-20. http://dx.doi. org/10.3748/wjg.v12.i1.17 PMID:16440411

7. Almasi Z, Rafiemanesh H, Salehiniya H. Epidemiology characteristics and trends of incidence and morphology of stomach cancer in Iran. Asian Pac J Cancer Prev. 2015;16 (7):2757-61. http://dx.doi.org/10.7314/apjcp.2015.16.7.2757 PMID:25854359

8. Marqués-Lespier JM, González-Pons M, Cruz-Correa M. Current perspectives on gastric cancer. Gastroenterol Clin North Am. 2016 Sep;45(3):413-28. http://dx.doi.org/10.1016/j.gtc.2016.04.002 PMID:27546840

9. Rahman R, Asombang AW, Ibdah JA. Characteristics of gastric cancer in Asia. World J Gastroenterol. 2014 Apr 28;20(16):4483-90. http://dx.doi.org/10.3748/wjg.v20.i16.4483 PMID:24782601

10. Veisani Y, Delpisheh A. Survival rate of gastric cancer in Iran; a systematic review and meta-analysis. Gastroenterol Hepatol Bed Bench. 2016 Sprin;9(2):78-86. PMID:27099666

11. Fitzmaurice C, Allen C, Barber RM, Barregard L, Bhutta ZA, Brenner H, et al. Global, regional, and national cancer incidence, mortality, years of life lost, years lived with disability, and disability-adjusted life-years for 32 cancer groups, 1990 to 2015: a systematic analysis for the global burden of disease study. JAMA Oncol. 2017 Apr 1;3(4):524-48. http://dx.doi.org/10.1001/jamaoncol.2016.5688 PMID:27918777

12. Farhood B, Geraily G, Alizadeh A. Incidence and mortality of various cancers in iran and compare to other countries: a review article. Iran J Public Health. 2018 Mar;47(3):309-16. PMID:29845017

13. Rastaghi S, Jafari-Koshki T, Mahaki B, Bashiri Y, Mehrabani K, Soleimani A. Trends and risk factors of gastric cancer in Iran (2005-2010). Int J Prev Med. 2019 May 17;10:79. http://dx.doi.org/10.4103/ijpvm.IJPVM_188_17 PMID:31198514

14. Tsugane S, Sasazuki S. Diet and the risk of gastric cancer: review of epidemiological evidence. Gastric cancer. 2007;10(2):75-83. http://dx.doi.org/10.1007/s10120-007-0420-0 PMID:17577615

15. Yusefi AR, Lankarani KB, Bastani P, Radinmanesh M, Kavosi Z. Risk factors for gastric cancer: a systematic review. Asian Pacific J Cancer Prev. 2018 Mar 27;19(3):591-603. http://dx.doi.org/10.22034/APJCP.2018.19.3.591 PMID:29579788

16. Park JY, von Karsa L, Herrero R. Prevention strategies for gastric cancer: a global perspective. Clin Endosc. 2014 Nov;47(6):478-89. http://dx.doi.org/10.5946/ce.2014.47.6.478 PMID:25505712

17. Sitarz R, Skierucha M, Mielko J, Offerhaus GJA, Maciejewski R, Polkowski WP. Gastric cancer: epidemiology, prevention, classification, and treatment. Cancer Manag Res. 2018 Feb 7;10:239-48. http://dx.doi.org/10.2147/CMAR.S149619 PMID:29445300

18. Rocco A, Nardone G. Diet, H. pylori infection and gastric cancer: evidence and controversies. World J Gastroenterol. 2007 Jun 7;13(21):2901-12. http://dx.doi.org/10.3748/wjg.v13.i21.2901 PMID:17589938 
19. Bae J-M, Lee EJ, Guyatt G. Citrus fruit intake and stomach cancer risk: a quantitative systematic review. Gastric Cancer. 2008;11(1):23-32. http://dx.doi.org/10.1007/s10120-007-0447-2 PMID:18373174

20. Bahmanyar S, Ye W. Dietary patterns and risk of squamous-cell carcinoma and adenocarcinoma of the esophagus and adenocarcinoma of the gastric cardia: a population-based case-control study in Sweden. Nutr Cancer. 2006;54(2):171-8. http://dx.doi. org/10.1207/s15327914nc5402_3 PMID:16898861

21. Dehdari T, Dehdari L, Jazayeri S. Diet-related stomach cancer behavior among Iranian college students: A Text Messaging Intervention. Asian Pac J Cancer Prev. 2016 Dec 1;17(12):5165-72. http://dx.doi.org/10.22034/APJCP.2016.17.12.5165 PMID:28124882

22. Salvador I, Mercado A, Bravo GL, Baldeón M, Fornasini M. Risk and protective factors for gastric metaplasia and cancer: a hospital-based case-control study in Ecuador. Nutr Hosp. 2015 Sep 1;32(3):1193-9. http://dx.doi.org/10.3305/nh.2015.32.3.9257 PMID:26319838

23. DeVellis RF. Scale development: theory and applications. Vol. 26. Thousand Oaks, CA: Sage Publications; 2016.

24. McGraw KO, Wong SP. Forming inferences about some intraclass correlation coefficients. Psychol Methods. 1996;1(1):30-46. https://doi.org/10.1037/1082-989X.1.1.30

25. Bravo G, Potvin L. Estimating the reliability of continuous measures with Cronbach's alpha or the intraclass correlation coefficient: toward the integration of two traditions. J Clin Epidemiol. 1991;44(4-5):381-90. http://dx.doi.org/10.1016/08954356(91)90076-1 PMID:2010781

26. Chiang H, Lin S. Psychometric testing of the Chinese version of nursing practice environment scale. J Clin Nurs. 2009 Mar;18(6):919-29. http://dx.doi.org/10.1111/j.1365-2702.2008.02433.x PMID:19017371

27. D'Elia L, Rossi G, Ippolito R, Cappuccio FP, Strazzullo P. Habitual salt intake and risk of gastric cancer: a meta-analysis of prospective studies. Clin Nutr. 2012 Aug;31(4):489-98. http://dx.doi.org/10.1016/j.clnu.2012.01.003 PMID:22296873

28. Yassibaş E, Arslan P, Yalçin S. Evaluation of dietary and life-style habits of patients with gastric cancer: a case-control study in Turkey. Asian Pac J Cancer Prev. 2012;13(5):2291-7. PMID:22901209

29. Wang T, Cai H, Sasazuki S, Tsugane S, Zheng W, Cho ER, et al. Fruit and vegetable consumption, Helicobacter pylori antibodies, and gastric cancer risk: a pooled analysis of prospective studies in China, Japan, and Korea. Int J Cancer. 2017 Feb 1;140(3):591-9. http://dx.doi.org/10.1002/ijc.30477 PMID:27759938

30. Chen P, Lin Y, Zheng K, Liu B, Wu C1, Yan W, Cai Y. Risk factors of gastric cancer in high-risk region of China: a population-based case-control study. Asian Pac J Cancer Prev. 2019 Mar 26;20(3):775-81. http://dx.doi.org/10.31557/APJCP.2019.20.3.775 PMID:30909684

31. Wang S, Freedman ND, Loftfield E, Hua X, Abnet CC. Alcohol consumption and risk of gastric cardia adenocarcinoma and gastric noncardia adenocarcinoma: a 16-year prospective analysis from the NIH-AARP diet and health cohort. Int J Cancer. 2018 Dec 1;143(11):2749-57. http://dx.doi.org/10.1002/ijc.31740 PMID:29992560

32. Hashemian M, Murphy G, Etemadi A, Dawsey SM, Liao LM, Abnet CC. Nut and peanut butter consumption and the risk of esophageal and gastric cancer subtypes. Am J Clin Nutr. 2017 Sep;106(3):858-64. http://dx.doi.org/o.3945/ajcn.117.159467 PMID:28768652

33. Navarro Silvera SA, Mayne ST, Gammon MD, Vaughan TL, Chow WH, Dubin JA. Diet and lifestyle factors and risk of subtypes of esophageal and gastric cancers: classification tree analysis. Ann Epidemiol. 2014 Jan;24(1):50-7. http://dx.doi.org/10.1016/j.annepidem.2013.10.009 PMID:24239095

34. Zhang FX, Miao Y, Ruan JG, Meng SP, Dong JD, Yin H, Huang Y, Chen FR, Wang ZC, Lai YF. Association between nitrite and nitrate intake and risk of gastric cancer: a systematic review and meta-analysis. Med Sci Monit. 2019 Mar 9;25:1788-99. http:// dx.doi.org/10.12659/MSM.914621 PMID:30850575

35. Polit DF, Beck CT. The content validity index: are you sure you know what's being reported? Critique and recommendations. Res Nurs Health. 2006 Oct;29(5):489-97. http://dx.doi.org/10.1002/nur.20147 PMID:16977646 